\title{
CONSIDERACIONES ÉTICAS PARA UNA MIRADA COMPREHENSIVA DE LA NATURALEZA
}

\author{
Augusto Castro Carpio
}

\section{Resumen:}

El artículo sugiere que para el abordaje de temas relacionados con la naturaleza se requiere de una mirada comprehensiva que nos permita repensar la importancia de contar con una conducta ética frente a la naturaleza. Para ello el autor desarrolla cuatro temas: primero, hace una revisión de la noción de ética a lo largo de la historia recogiendo reflexiones de pensadores como Aristóteles, Descartes, Leibniz y Einstein, y cómo conciben la relación entre sociedad y la naturaleza. Un segundo eje de reflexión se establece en torno al concepto de vida, para distinguir entre vida racional o inteligente y la vida en su acepción más amplia. Desde esta perspectiva se pregunta ¿de qué vida estamos hablando cuando pensamos en la noción de naturaleza viva o de ecosistemas vivos? En el tercero, desde una mirada crítica al antropocentrismo - desde el cual siempre se ha concebido a la naturaleza-, se pregunta si a partir de esta perspectiva se puede hablar de una relación ética con la naturaleza, entendiendo así la ética como hacer lo que corresponde. Como último y cuarto punto propone que los nuevos paradigmas para saber vivir en el mundo hay que trabajarlos desde una perspectiva interdisciplinaria que tenga como horizonte la sostenibilidad.

\section{Palabras clave:}

Ética, Naturaleza, Vida, Vida racional, Antropocentrismo, Modernidad, Interdisciplina, Sostenibilidad, Comprehensión. 


\title{
Ethical considerations for a comprehensive approach to Nature
}

\begin{abstract}
:
An approach to Nature-related topics requires a comprehensive view, rethinking the importance of committing to ethical conduct with regards to Nature. To do that, the author explores four themes. First, he reviews the notion of ethics throughout History, referring to the relationship between society and Nature in Aristotle, Descartes, Leibniz and Einstein's work. Second, the author discusses the concept of life, contrasting the concept of rational or intelligent life with a more ample definition of life. What is the life notion we have in mind when we discuss about alive ecosystems and Nature? Third, taking the traditional anthropocentric view from a critical perspective, the author questions whether it is possible to ensure an ethical relationship with Nature based on such traditional viewpoint. Finally, the author argues that the new paradigms on knowing how to live in the world need to be developed from an interdisciplinary perspective, aiming at sustainability.
\end{abstract}

\section{Keywords:}

Ethic, Nature, Life, Rational life, Modernity, Anthropocentrism, Interdisciplinarity, Sustainability, Comprehensive approach.

\section{Augusto Castro Carpio}

Doctor en Estudios Latinoamericanos por la Universidad de Tokio, Japón. Magíster en Filosofía, Licenciado en Filosofía y Bachiller en Humanidades con mención en Filosofía por la Pontificia Universidad Católica del Perú. Profesor Principal del Departamento de Ciencias Sociales de la PUCP. Ex director del Centro de Investigaciones Sociológicas, Económicas, Políticas y Antropológicas de la PUCP (CISEPA - PUCP). Ex presidente del Comité de Ética para la Investigación con Seres Humanos y Animales de la PUCP. Coordinador de la Red Latinoamericana de Estudios de Sociedad y Ambiente de CLACSO. Actualmente es director del Instituto de Ciencias de la Naturaleza, Territorio y Energías Renovables de la PUCP (INTEPUCP) y coordinador del grupo de investigación Ética, Ambiente y Sociedad del INTE-PUCP.

Entre sus principales publicaciones están: Río + 20 Desafíos y perspectivas (2015); Reconstruir y educar: tareas de la Nación. 1885-1905, y Una educación para re-crear el país. 1905-1930, v.7 y v.8 de la Colección Pensamiento Educativo Peruano (2013); La responsabilidad social empresarial: reflexiones sobre los planes estratégicos de socios estratégicos. Caso Antamina (2012); Los nuevos retos de la política social en el Perú: articulando la academia con la gestión pública (2011), La filosofía entre nosotros: cinco siglos de filosofía en el Perú (2009); El desafío de las diferencias: reflexiones sobre el Estado moderno en el Perú (2008); entre otros.

Correo electrónico: acastro@pucp.pe 


\section{Introducción}

Para todos es un supuesto básico pensar que debe existir una buena relación con la naturaleza y ello no parece algo fuera del sentido común. Pero, en términos más precisos, este supuesto no se ha investigado con acuciosidad y se vuelve un desafío cuando enfrentamos como seres humanos problemas relacionados con el medioambiente y la naturaleza.

La actual situación nos lleva a precisar el significado de la ética y a revisar cómo se han asumido o incorporado, en su desarrollo, los temas relacionados con la naturaleza. La emergencia de la bioética en estas últimas décadas, por poner un ejemplo, es parte del camino recorrido por la ética en su esfuerzo por pensar cuestiones relacionadas con los seres vivos en un espectro más amplio que la sola vida humana. Consideramos, por ello, que para el abordaje de los temas relacionados con la naturaleza y el ambiente se requieren, por parte de la ética, de nuevos análisis y de una mirada comprehensiva.

La razón de esto, desde nuestro punto de vista, está en que la reflexión ética ha estado alejada de los temas de la naturaleza y ha estado más centrada en la discusión social y política. Una de las explicaciones de este alejamiento puede estar en que los modelos de la ética han sido pensados desde paradigmas anclados principalmente en modelos antropocéntricos y desligados del mundo natural. La modernidad, no cabe duda, tiene una clara responsabilidad en este asunto. Todo su esfuerzo ha sido concentrarse en el sujeto y alejarse de los objetos y del mundo; es decir, en muchos casos, subordinó - cuando no eliminó- el rol de la naturaleza. Esto ha acarreado, sin lugar a dudas, una exagerada comprensión del papel del sujeto en detrimento del mundo.

La reflexión sobre la naturaleza nos obliga a una comprensión más profunda de lo que somos como seres vivos e inteligentes y a entender que no somos los únicos que tienen estas particularidades. Urge, entonces, una necesaria reflexión sobre el sentido de la vida, que no puede ser entendida solo como vida racional o inteligente: la de los seres humanos o la de los seres vivos más desarrollados, sino desde una perspectiva más amplia. 
Una nueva comprensión de la vida, que valore y a la vez tome distancia de la singularidad de la vida racional, puede permitirnos apreciar mejor las diversas formas de vida existente. Esto, incluso, puede darle un nuevo sentido y contenido a lo que hemos llamado por siglos la vida racional de los seres humanos.

El objetivo de nuestra reflexión está en comprender la importancia de una conducta ética frente a la naturaleza y los desafíos que ello implica. Esto debe significar la apuesta por rehacer nuestra manera de pensar y de actuar en el mundo.

En este texto buscaremos remarcar algunas ideas que nos parecen centrales en esta perspectiva. La primera es la de un acercamiento a la noción de ética y a su proceso de reflexión, intentando destacar la problemática de la naturaleza. La segunda, la discusión en torno al concepto de vida que manejamos, distinguiendo entre inteligencia y vida. La tercera, un balance del papel de la práctica humana en la relación con el mundo. Finalmente, la cuarta, la necesidad de contar con una mirada interdisciplinaria y con un nuevo horizonte de sostenibilidad para avanzar en comprender qué significa saber vivir en el mundo.

\section{La reflexión ética}

\subsection{El antiguo sentido de la ética}

La vida social es expresión de las diversas relaciones humanas y naturalmente, entre ellas, de las éticas. Decir que la sociedad tiende al bien es algo razonable (Aristóteles 1985) ${ }^{1}$; incluso podríamos observar una cierta identificación entre el concepto de ética y el de sociedad cuando valoramos - por ejemploa esta última como una asociación de ciudadanos (Aristóteles 1986)², es decir, de personas iguales ante la ley y con los mismos derechos ${ }^{3}$. Por esto podemos también pensar que existe una correlación entre una práctica anti-social y lo que llamamos un comportamiento no ético. Habría entonces una relación entre el actuar ético y el ser ciudadano por un lado, y por otro, entre el ser

1 En términos generales podemos sostener que desde Sócrates y Platón, y que ciertamente continúa Aristóteles y las diversas escuela filosóficas, la cuestión del bien es el tema crucial en la reflexión ética.

2 En la concepción del Estado, tanto en el antiguo como en el moderno, la referencia a la ciudadanía es fundamental. Los griegos siempre entendieron la ciudadanía como una construcción política que va más allá de lo biológico.

3 Recordemos que el sentido del derecho va de la mano con la idea de isonomía, es decir de la igualdad ante la norma. 
corrupto y violar las leyes de la comunidad (Platón 1986). Podríamos afirmar así que no hay una gran distancia entre lo que llamamos sociedad y lo que llamamos conducta ética; ciertamente que la sociedad, por el ejercicio del ciudadano, lleva el ideal de vida buena propio de la condición ciudadana.

El ideal de comportamiento que tiene la vida buena en comunidad ha sido para muchos un elemento que muestra el grado de civilización de un pueblo ${ }^{4}$. De ahí, por ejemplo, que los antiguos griegos y romanos diferenciaran nítidamente entre bárbaros y ciudadanos. No queremos dejar de reconocer, sin embargo, el claro etnocentrismo que está detrás de esta afirmación, pero tampoco conviene descartar lo que está también implícito en ella y que nos parece rescatable: que la comunidad debe estar regida por leyes y acuerdos entre los ciudadanos. La civilización, en esta perspectiva, ha sido y es fruto de una intensa y consciente vida de respeto y de derechos entre los miembros de una comunidad. No hay manera de entender la comunidad o la sociedad sin una claro fundamento ético. Quizá los pensadores antiguos como Aristóteles no estaban tan lejos de la verdad cuando afirmaban que la comunidad es una construcción moral.

Durante siglos, la mirada humana en términos de conducta moral ha estado regida por el sentido de comunidad. El ideal moral de la vida de cualquier individuo ha estado articulado a su comportamiento en la comunidad. Uno de los muchos significados del vocablo ética, que puede entenderse como hacer lo que corresponde (Mc Intyre 1982) -e implicaría no cualquier comportamiento sino el adecuado, el mejor - nos puede ayudar a pensar en esta perspectiva.

En este sentido todos los seres humanos hemos sido formados con ideales morales que responden de manera categórica al ideal de la vida buena en cada comunidad. Las virtudes han expresado, por ello, el comportamiento ideal exigido al individuo. La justicia como la principal de las virtudes, según sostenía Aristóteles y que se encuentra presente en muchos pueblos y culturas del mundo, refleja esta orientación fundamental: la conducta ética es la expresión de la vida buena en un pueblo, comunidad o sociedad (Aristóteles 1985).

\subsection{Las pruebas de la existencia de Dios están en la naturaleza}

Un buen momento para comprender la relación entre ética y naturaleza se encuentra en la discusión medieval. En la vieja discusión escolástica la

4 Entendemos como civilización los ideales comunitarios que están alrededor de lo que los antiguos llamaron la civitas. 
distinción entre esencia y existencia se mantuvo con mucha fuerza durante muchos siglos, y fue Santo Tomás entre otros filósofos y teólogos, quien recogió y fundamentó esta diferencia fundamental para los escolásticos. Para Santo Tomás, heredero del aristotelismo, recoger esta distinción suponía mantener un pie en la tierra: la existencia era una realidad objetiva. Santo Tomás, atemperado el platonismo, desarrolló su propuesta de hacer congruentes las ideas o las esencias con la realidad material; un maridaje adecuado entre ideas y cosas, entre esencia y existencia parecía lo adecuado para reconocer tanto la realidad de la conciencia humana como la realidad de la naturaleza.

De la misma manera que Aristóteles, Santo Tomás no era ni materialista ni empirista. Su interés estaba en una adecuada relación entre res et natura y también entre fe y razón. Sobre ello nos dice Étienne Gilson:

Busquemos, pues, en las cosas sensibles, cuya naturaleza es proporcionada a la nuestra, un punto de apoyo para elevarnos a Dios.

Todas las pruebas tomistas ponen en juego dos elementos distintos: la constatación de una realidad sensible que requiere una explicación y la afirmación causal, que tiene por base a esta realidad sensible y por cima a Dios (1976: 493).

Desde nuestro punto de vista, los escolásticos nunca negaron la capacidad de agencia de la naturaleza humana; todo lo contrario, la reconocieron, pero les hubiera parecido erróneo solo aceptar a la conciencia humana como la única realidad. En la reflexión de Santo Tomás queda claro que la naturaleza está articulada con la existencia de Dios, pues de él obtiene su existencia. No hay una ruptura al estilo sujeto/objeto propio de la modernidad, esto implica que la naturaleza pueda ser comprendida como creación y no como un objeto de análisis racional. La naturaleza tenía un rol en la escala hacia la perfección divina, pero ciertamente subordinado. La teología cristiana no divinizó nunca a la naturaleza, sino que la entendió siempre como creada por Dios y diferente a él.

La argumentación de Santo Tomás buscó integrar a la naturaleza en la perspectiva divina, no solo para señalar que fue creada por Dios sino para tratar de mostrar que ella es una prueba de su bondad y que expresa inequívocamente la existencia de Dios. Podemos discutir la posición de Santo Tomás en si naturaleza es una prueba de la existencia de Dios o no, lo que no podemos discutir es que para él y para muchos en esta época la naturaleza estaba articulada a sus creencias más vitales y jugaba un papel central en sus vidas. 


\subsection{Modernidad: ética y naturaleza}

Rodolfo Mondolfo empieza un trabajo sobre Leonardo de Vinci con una interesante discusión:

En el año 1452, el mismo del nacimiento de Leonardo de Vinci, el humanista florentino Giannozzo Manetti acababa de escribir, por invitación del rey Alfonso de Nápoles, su obra De dignitate et excellentia hominis, que al iniciar las celebraciones renacentistas del poder creador del espíritu humano, quería reivindicar la dignidad del hombre contra el vilipendio medieval, expresado típicamente -a fin de humillar el orgullo humano- en el De miseria humanae vitae del Papa Inocencio III. "Tú hombre (decía Inocencio), andas investigando hierbas y árboles; pero éstos producen flores, hojas y frutos, y tú produces liendres, piojos y gusanos; de ellos brota aceite, vino y bálsamo, y de tu cuerpo esputos, orina y excrementos." Reaccionaba Manetti, proclamando que los frutos del hombre no están constituidos por estas sucias materias, sino por las obras de su inteligencia y de su acción creadora, para las cuales el hombre ha nacido como integrador y perfeccionador de la naturaleza mediante sus artes e inventos (Mondolfo 1968: 11).

Con la irrupción del mundo moderno las cosas, las ideas y los comportamientos se transformaron de manera radical. La mayor transformación se operó en el propio sujeto moderno. Los tiempos modernos avanzaron en una dirección que privilegiaba la conciencia humana: la realidad del mundo dependería del sujeto. Esto ofrecería innegables espacios para el desarrollo de la subjetividad, pero también algunas y graves cegueras frente a la naturaleza y al cosmos. El ser humano, con el advenimiento del mundo moderno, se sintió espíritu, idea y conciencia; no se reconoció más como parte de la naturaleza.

Recordar a René Descartes en esta revisión puede ser importante. Con él, dicen muchos, se inicia la modernidad filosófica. Su conocido cogito ergo sum preside la cultura y el pensamiento moderno.

Y en verdad, he advertido que vosotros, Señores, no sólo aseguráis con todos los Teólogos que la existencia de Dios se puede probar por razón natural, sino también que de la Santa Escritura se infiere que su conocimiento es mucho más claro que el que se tiene de muchas cosas creadas y que, en efecto, es tan fácil que quienes no lo tienen son culpables. Como es manifiesto por estas palabras de la Sabiduría, capítulo 13, en donde se dice que $s u$ 
ignorancia es imperdonable, pues si su espíritu ha penetrado tan adelante en el conocimiento de las cosas del mundo, ¿cómo es posible que no hayan encontrado más fácilmente al soberano Señor? Y en los Romanos, capítulo primero, se dice que son inexcusables, y aun en el mismo pasaje, por medio de estas palabras, lo que se conoce de Dios es manifiesto en ellos, parece que se nos advierte que todo lo que puede saberse de Dios puede ser mostrado por medio de razones que no es necesario buscar sino en nosotros mismos, y que únicamente nuestro espíritu es capaz de suministrar. Por este motivo he pensado que no sería desatinado que hiciera ver aquí por qué medios puede verificarse esto y que vía hay que seguir para alcanzar el conocimiento de Dios con mayor facilidad y certeza de lo que conocemos las cosas de este mundo (Descartes 1967: 202).

El mundo está pensado desde el sujeto y no tiene existencia en tanto él no lo piense. Repasemos estas palabras que acabamos de citar: «[...] lo que puede saberse de Dios puede ser mostrado por medio de razones que no es necesario buscar sino en nosotros mismos [...]» (Descartes 1967: 202). Esto implica una manera de pensar que descubre que el espíritu humano es el fundamento para el conocimiento de Dios y que, por ende, el verdadero conocimiento no está fuera sino en nosotros mismos. Las pruebas de la existencia de Dios a partir de la naturaleza, sugeridas por Santo Tomás, no tienen, en realidad, ya mucha relevancia.

Ciertamente que conviene precisar - en defensa del pensamiento moderno- que parte del debate epistemológico de la época insistía en una nueva manera de pensar que recolocara a la ciencia en su lugar y que no estuviera fundada sobre creencias o dogmas. La ciencia debía basarse en ideas claras y distintas, como lo señaló el propio Descartes. Pero faltaríamos a la verdad si redujésemos todo esto a un debate exclusivamente epistemológico. El debate marcó una nueva disposición del pensamiento humano que se sintió, a partir de este momento, el centro del universo, de la realidad y de la sociedad.

Otro momento importante de la reflexión moderna es la crítica que hace Leibniz a la teoría de la gravedad de Isaac Newton. En ella podemos advertir la misma disposición.

118. Yo había objetado que una atracción propiamente dicha, o a la escolástica, sería una operación a distancia, sin medio. Se responde aquí que una atracción sin medio sería una contradicción. Muy bien ¿pero cómo se entiende entonces, cuando se quiere que el Sol a través de un espacio vacío atraiga al globo de la tierra? ¿Es Dios 
quien sirve de medio?, pero esto sería un milagro, si alguna vez los hubo, sobrepasaría las fuerzas de las criaturas.

119. ¿O son quizás algunas sustancias inmateriales, o algunos rayos espirituales, o algún accidente sin sustancia, alguna especie como intencional, o cualquier otro no sé qué, el que debe pretender constituir este pretendido medio? Cosas de las que parece que se tiene todavía buena provisión en la mente, sin explicación bastante. 120. Este medio de comunicación es, se dice invisible, intangible, no mecánico. Se podría agregar con el mismo derecho, inexplicable, no inteligible, precario, sin fundamento, sin ejemplo.

121. Pero es regular, se dice, es constante, y por consecuencia natural. Respondo que no podría ser regular sin ser razonable; y que no podría ser natural sin ser explicable por las naturalezas de las criaturas.

122. Si este medio que hace una verdadera atracción es constante, y al mismo tiempo inexplicable por las fuerzas de las criaturas, y si es verdadero además, es un milagro perpetuo. Y si no es milagroso, es falso; es una cosa quimérica, una cualidad oculta escolástica (Leibniz 1957: 178-179).

Leibniz sostiene, en verdad, que la gravedad no es una realidad y que no hay manera de probar que realmente exista. Para él, solo existe en la cabeza de Newton.

Tenga o no razón Leibniz, el debate entre los pensadores modernos y científicos está demarcado por las fronteras de la subjetividad. El ejemplo de la crítica a la teoría de la gravedad de Newton nos permite comprender el inmenso peso del criterio del científico en la materia. La realidad ajena al sujeto - si se puede entender así- no existe. En sentido estricto, Newton concedió a la realidad un espacio propio diferenciado de la conciencia y Leibniz lo criticó.

La perspectiva de Albert Einstein no se aleja de la orientación de Descartes y de Leibniz cuando señala que la ciencia reposa en el juicio del sujeto.

Es la teoría general de la relatividad la que ha mostrado de manera convincente cuánto esta opinión es errónea. Pues esta teoría ha hecho ver que nos era posible, partiendo de principios de base muy alejados de los de Newton, justificar la totalidad de los datos de la experiencia de una manera más completa y más satisfactoria que la que permitían los principios de Newton (Einstein 1933: 11). 
Einstein, no obstante, se pregunta

Si es verdad pues que la base axiomática de la física teórica no puede ser obtenida por una inferencia a partir de la experiencia, sino que debe ser de una libre invención, ¿tenemos derecho a esperar que encontraremos el buen camino? Mucho más: ¿existe realmente el buen camino en otra parte distinta de nuestra imaginación? (1933: 12).

\section{Y se responde:}

A lo cual respondo con una perfecta seguridad que existe, al menos en mi opinión, el buen camino y, además, que está en nuestro poder encontrarlo. Nuestra experiencia hasta este día nos justifica en nuestra certeza de que el ideal de la simplicidad matemática está realizado en la naturaleza. Estoy convencido de que la construcción puramente matemática nos permite descubrir los conceptos y las leyes que los enlazan, los cuales nos dan la clave para comprender los fenómenos de la naturaleza [...] En cierto sentido, pues, tengo por verdadero que el pensamiento puro es competente para comprender lo real, como los antiguos lo habían soñado (1933: 13).

Estas referencias a Einstein nos llevan a una interesante reflexión. Siguiendo la lógica de nuestro trabajo, lo que nos impresiona de sobremanera son las frases «[...] de que el ideal de la simplicidad matemática está realizado en la naturaleza.» y también «[...] que el pensamiento puro es competente para comprender lo real, como los antiguos lo habían soñado.» (1933: 13). Estas expresiones nos muestran una comprensión más profunda de la relación entre ser humano y naturaleza, no hay distinción entre este y la naturaleza. Así, el ser humano tiene la posibilidad, según Einstein, de conocer cómo opera la naturaleza a través de su pensamiento matemático. La experiencia es importante, pero en su propia naturaleza pensante, como lo sugirió Descartes, está la posibilidad del conocimiento de lo real.

Con claridad apreciamos que con Einstein se produce una renovación del paradigma científico que puntualiza que el conocimiento científico depende decisivamente del punto de vista del científico. Es un cambio en el conocimiento de la realidad. No es, en sentido estricto, una discusión en torno a la realidad sino a la manera en que los seres humanos la comprenden y la asimilan. La revolución relativista de Einstein coloca sus fundamentos en la manera de pensar y de juzgar del sujeto, y define que solo podemos conocer de manera relativa y no de manera absoluta. Con su crítica podemos 
reconocer que la mirada absoluta de la modernidad inicial tenía un límite claro y que esta primera mirada solo veía lo que quería ver y, probablemente, no estaba interesada en conocer a profundidad la realidad.

\section{La cuestión de la vida}

Hemos vuelto en la actualidad a replantear los viejos temas que preocuparon a los antiguos y modernos. No se trata de un regreso a sus concepciones sobre la naturaleza, sino de una revisión profunda que nos ayude hoy a pensar cuál es nuestro lugar en el cosmos y cuál nuestro papel con la naturaleza. Nos parece importante que desarrollar algunas ideas para distinguir entre vida y vida inteligente ayudaría a comprender mejor el vínculo entre la naturaleza y la condición humana.

\subsection{Naturaleza viva}

¿La naturaleza está realmente viva? Esta es una pregunta central para nuestra reflexión y conviene, por ello, enfrentar la cuestión de si la naturaleza está viva. Esto nos lleva necesariamente a otras preguntas: ¿los diversos ecosistemas están vivos?, ¿de qué vida estamos hablando cuando pensamos en la noción de naturaleza viva o de ecosistemas vivos ${ }^{25}$

No podemos dejar de reconocer que en la naturaleza coexisten diversas formas de vida. Para recordar a los antiguos, Aristóteles (1993), en sus estudios sobre la naturaleza como Parva Naturalia, señaló que en ella hay movimiento, ciclos, reproducción y vida. Incluso, podríamos sostener que para ellos la dinámica vital humana era parte integrante de la dinámica vital de la naturaleza. Pero los antiguos, además, distinguieron entre vida y vida inteligente. Ellos sostuvieron que la vida de la naturaleza era real, pero no era vida consciente de sí, como sí lo era la vida humana. La vida consciente de síla entenderemos como 'vida inteligente'. Un desafío actual —aunque los antiguos nunca lo negaron- es que la inteligencia no solo es un atributo de los seres humanos, sino de muchísimos seres vivos.

Creemos que es necesario reflexionar y hacer todo el esfuerzo por distinguir con claridad entre vida y vida inteligente. Para empezar, esta distinción no es nueva; ya se hablaba hace milenios de vida sensitiva y de vida racional. Durante siglos hemos considerado a los animales y a las plantas con seres de vida sensitiva, y hemos reservado para la especie humana la vida racional.

5 Aquí conviene volver a la noción de vida que viene de Aristóteles y naturalmente de los pueblos antiguos. 
Lo más importante aquí es constatar que la inteligencia ha existido siempre y, de diversas formas, en todas las especies. Dentro de los parámetros de la lucha por la sobrevivencia, por poner algún ejemplo, todas las especies de plantas y animales se han adaptado a las condiciones naturales. Las que no lo hicieron ya no están con nosotros.

Nuestra pregunta sería: ¿no es acaso la adaptación uno de los indicadores más relevantes cuando hablamos de inteligencia? La adaptación muestra o señala los esfuerzos de todo organismo para mantenerse vivo y sobrevivir. La inteligencia anida en ese esfuerzo por vivir; pero podemos pensar que las plantas y los animales realmente no elijen sus formas de adaptación. ¿Solo podemos considerar como elementos de vida sensitiva el esfuerzo de adaptación y sobrevivencia? ¿Cómo queda la inteligencia que ello lleva consigo? ¿No hay vida consciente en esta empresa? Tenemos todavía bastantes temas oscuros en la determinación de los límites entre la vida racional de los seres humanos y la llamada vida sensible de plantas y animales.

La razón de que esto nos parezca así es porque cada vez que pensamos lo hacemos con los criterios de nuestra racionalidad y lo que no calza con la manera de pensar que tenemos no puede ser considerado racional. Probablemente estamos ante un abismo que no podemos franquear, pero a pesar de ello estamos en condiciones de sospechar y de saber que existen lógicas distintas a las humanas que han estado detrás y que permiten la sobrevivencia de todas las especies vivas. Su sola presencia en la naturaleza lo evidencia.

Nuestro interés en este texto no está en la determinación de cuánto son conscientes de sí los seres que están vivos. Nuestra preocupación es si la naturaleza está viva y cómo es esta si verdaderamente lo afirmamos. Pensamos que la naturaleza no es una entelequia, ni un ente, sino que es un sistema vivo que opera orgánicamente: es, a juicio nuestro, el espacio que permite todo tipo de vida.

Trataremos de explicar estas ideas con algunas analogías. Lo que sucede en un nivel micro, por ejemplo, con el cuerpo humano, tiene características análogas con lo que sucede en el nivel macro, con los ecosistemas o con el planeta. Así como no asignamos vida propia a un pelo o a un brazo humanos porque la vida humana está asociada principalmente con la noción de conciencia - o de alma o de ánima- - y no de una parte del cuerpo, así tampoco se la asignamos a un río, a una montaña o a un ecosistema porque son elementos que por sí mismos no definen el significado de vida.

Tendríamos que preguntarnos si la naturaleza es consciente de sí misma en la definición de naturaleza viva. No sabemos si la naturaleza tiene conciencia de sí, aunque sabemos que está viva. Tales de Mileto señaló que 
en el mundo "todo estaba penetrado de dioses», que todo estaba penetrado de vida. Según él, la tierra era un animal vivo (Kirk y Raven 1981: 138-144).

Todos los panteístas ${ }^{6}$, que han seguido esta orientación en mayor o menor medida, han creído siempre en la conciencia de sí de la naturaleza y, por ello, la divinizaron. El pensamiento mítico, en casi la mayoría de los pueblos antiguos, ha considerado también a la naturaleza como un ser consciente de síp; incluso, ha identificado su centro de poder sagrado en alguno de sus elementos primordiales.

\subsection{La responsabilidad de ser la conciencia viva de la naturaleza}

Hasta aquí seguimos en la dicotomía ser humano y naturaleza, como dos asuntos sin relación y sin vínculo. Lo real es que el ser humano es parte de la naturaleza, es naturaleza. El hecho de que sea naturaleza consciente de sí e inteligente no lo hace diferente de ella.

Si partimos de esta afirmación sería más sencillo comprender el rol del ser humano en la naturaleza. Cabría preguntarse, ¿qué y cuál sería la conciencia de sí de la naturaleza? Nuestra posición apunta a reconocer al ser humano como la conciencia de sí más elevada de la naturaleza.

Esta discusión tampoco es nueva. Para muchos la llamada conciencia de la naturaleza se ha expresado, principalmente, en la naturaleza humana. El tema, desde nuestra óptica es si verdaderamente la conciencia humana vendría a ser la conciencia de sí de la naturaleza. Según la tradición antropocéntrica, muy común en nuestra cultura occidental y cristiana, la vida humana es el vértice de la vida natural al ser la conciencia de la naturaleza, la conciencia del mundo. Los seres humanos serían la conciencia de sí del mundo natural.

De acuerdo con lo señalado, una vida consciente como es la humana no solo debería tomar como punto de referencia a la salud de su especie, como lo plantea Anthony Giddens (2010) en su polémica con los verdes alemanes, sino que debería tomar como punto de referencia a toda la naturaleza, porque no es solo la conciencia de su especie, sino que es la conciencia del mundo.

Esto nos obliga a superar, como acabamos de señalar, la dicotomía moderna que escinde al sujeto del objeto, al ser humano de la naturaleza, y nos lleva a comprender a la especie humana también como naturaleza y no solo como conciencia o subjetividad. Einstein puede decir que el ideal de la simplicidad matemática está realizado en la naturaleza porque considera

\footnotetext{
6 Estamos considerando la noción de panteísta a la idea que percibe la presencia de lo sagrado en todas las cosas y en la naturaleza.

7 Esto ha sido considerado como una especie de animismo prefilosófico.
} 
implícitamente que no tendría por qué haber dificultad de comprensión de la naturaleza para los seres humanos, porque estos al ser parte de ella tienen la capacidad racional de entender la simplicidad matemática de aquella.

Por lo expuesto, tomar solo como punto de responsabilidad ética a la propia especie humana sería un grave error. Con ello caeríamos en el más extremo idealismo: miraríamos a la naturaleza y a nosotros mismos en el espejo de la sola conciencia humana. Ese ha sido parte del camino recorrido por la modernidad. Haber concentrado toda la riqueza y la vida natural del mundo en la especie humana ha generado gravísimas miopías y terribles problemas que hoy tenemos que enfrentar.

Hemos construido una racionalidad que no ha sido capaz de ver realmente el mundo porque no ha mirado más allá de sus intereses y, lo peor, los ha confundido permanentemente con los de la naturaleza. Incluso, hemos considerado más real el conocimiento y la clasificación lógica que hemos hecho del mundo que el mundo mismo.

\subsection{El desarrollo de la bioética}

Desde principios del siglo XX ha empezado una severa crítica a este estrecho paradigma de la modernidad que restringe gravemente la mirada del mundo. Lo lamentablemente del paradigma inicial moderno es que no valoró ni consideró lo que estaba obligado a apreciar y a observar: la dimensión de la relación entre naturaleza y sociedad humana. La reducción de la naturaleza a un simple objeto de conocimiento, dando pie con ello a su explotación, ha generado problemas muy serios al mundo de hoy. Nos da la impresión que hoy en día se recusa la vieja idea de mundo que fuera pensada por el sujeto moderno. La naturaleza, es, ciertamente más agente que lo que pensamos y ello coloca en otro nivel la comprensión del mundo y del ser humano en él.

La transformación de la vida privada y la reivindicación del rol de la mujer, por ejemplo, han tardado también varios siglos en ser reconocidos -y todavía no podemos afirmar que su reconocimiento sea total-, siendo asuntos fundamentales de la naturaleza humana; lo mismo ha sido con el reconocimiento de pueblos, de culturas y de etnias. En esta línea conviene subrayar la impresionante ausencia en la cultura subjetiva moderna de considerar a la naturaleza como una realidad viva.

Desde fines de la Segunda Guerra Mundial se empezó a utilizar el vocablo bioética. El nuevo concepto, que con el correr de las últimas décadas se ha fortalecido y ha adquirido mayor peso y consistencia, nació como respuesta a las atrocidades de los nazis y de los militaristas japoneses durante la Segunda Guerra Mundial. Tuvo una formulación inicial el 20 de 
agosto de 1947 en el famoso Código de Nuremberg, que sancionó el uso de experimentos con seres humanos.

Esta nueva perspectiva ética marcó un claro reconocimiento de la vida aunque estuviera inicialmente solo vinculada a los seres humanos y, en particular, a los temas de salud humana ${ }^{8}$. No obstante, la bioética, en su sentido más profundo, tenía que ver más estrictamente con la relación entre el ser humano y la vida de las plantas y los animales como lo propuso Fritz Jahr'. No nos llama la atención, por eso, que la bioética haya trascendido el campo de la salud humana y se haya interesado cada vez más por la relación ética con los animales.

Con la reflexión sobre la bioética estamos ante el redescubrimiento de que la vida no es un universo que se reduce a la vida humana y que no depende exclusivamente de la especie humana. Todo lo contrario. La especie humana es parte de ese horizonte universal que llamamos vida. El que la vida no sea solo inteligente, es decir, consciente de sí, en muchos seres vivos de la naturaleza, no hace de ninguna manera que la vida de estos sea menos vida.

La bioética intenta responder a la pregunta ¿qué significa hacer lo que corresponde en relación con la existencia y con la vida? Esta ha sido la pregunta que la bioética ha intentado responder y normar: la de establecer las relaciones entre los seres humanos y los seres vivos, y con ello contar con un comportamiento ético adecuado en este tema.

\section{La crítica a la práctica humana y la propuesta de saber vivir en el mundo}

\subsection{Una mirada demasiado antropocéntrica de la naturaleza}

Pensamos que no tenemos un concepto preciso que exprese la relación entre la comunidad humana y la naturaleza, en términos generales. La razón podría estar en que la naturaleza se considera como un elemento subordinado, como solo un supuesto necesario de la vida humana. Las miradas sobre la naturaleza tienen, desde esta perspectiva, una clara orientación antropocéntrica; ciertamente, unas más radicales que otras.

Para una concepción marcadamente antropocéntrica la naturaleza es considerada como una especie de insumo, como una materia prima, como un elemento básico para el desarrollo de la especie humana. En esta concepción no se puede concebir una relación de igualdad entre algo que es pensado

8 El Código de Nuremberg tiene relación con el consentimiento voluntario para cuestiones médicas.

9 Fritz Jahr fue un pastor protestante, teólogo, filósofo y educador alemán creador del término Bioética en 1926, al cual hace referencia en el artículo Ciencias de la vida y la moral. 
como un ingrediente y la vida humana misma. Una relación ética se da entre iguales y no entre desiguales; la relación ética sería - desde este punto de vista- exclusiva de la vida inteligente, es decir, solo entre seres humanos. No podría haber entonces relaciones éticas entre vida inteligente y vida no tan inteligente, y menos aún, entre cosas inertes como las montañas o los ríos y las personas. Esta orientación ha justificado que todo en el mundo estuviera pensado para el exclusivo beneficio del ser humano.

Una mirada que modera este antropocentrismo radical y que reduce la relación desigual con la naturaleza es la llamada preocupación por el ambiente y la naturaleza, por los recursos naturales, por los ecosistemas, entre otros asuntos afines. Se trata de una mirada que busca reconciliar el crecimiento económico con el desarrollo humano; una preocupación que busca conservar los bienes de la naturaleza para el beneficio de los seres humanos y sus futuras generaciones. Estocolmo 72, Río 92, el Informe Brundtland y Río + 20 se encuentran en esta orientación conservacionista. No se ha abandonado la mirada antropocéntrica, solo se la ha limitado y criticado.

La pregunta es si a partir de una perspectiva estrictamente antropocéntrica se puede hablar de una relación ética con la naturaleza, entendiendo la ética como hacer lo que corresponde. Nos parece que es difícil. Hay que ir más allá.

\subsection{El equívoco comportamiento de los seres humanos}

Ser la conciencia del mundo no significa necesariamente que los seres humanos hagan adecuadamente lo que corresponde, es decir, que harán el bien. La actual problemática ambiental, por ejemplo, muestra esto con claridad: el uso desmedido e irresponsable de los residuos fósiles ha generado problemas gravísimos. Ciertamente que si nos vemos obligados a hablar de ética es porque simplemente los seres humanos no siempre hacen lo que tienen que hacer y que las relaciones humanas no expresan muchas veces comportamientos adecuados.

Lo mismo podría decirse del papel de la bioética, que emerge como disciplina para determinar y normar el comportamiento adecuado y las relaciones de los seres humanos y los seres vivos. La brutal experiencia de los campos de exterminio nos mostró la necesidad de señalar límites y normas. El terrible deterioro de la biodiversidad también ha reclamado normas y comportamientos para con las plantas y los animales.

La práctica humana para asegurar su sobrevivencia ha modificado claramente el entorno y debido a ello ha logrado un altísimo crecimiento poblacional. No es un secreto que en este esfuerzo nuestra especie ha hecho y hace uso de residuos fósiles para generar sus fuentes de energía; el uso de estos fósiles ha generado gases de efecto invernadero que han elevado la 
temperatura y han generado con ello muchos de los desastres que ya estamos viviendo. Hoy día es casi un consenso en la comunidad científica y académica mundial sostener el carácter antrópico del cambio climático.

Los impactos del calentamiento global se expresan en diversos puntos: deglaciación, desertificación, pérdida de la biodiversidad, calentamiento del mar e incremento de sus niveles, entre otros, los cuales aumentan las enfermedades y la vulnerabilidad de los pobres que viven vinculados al entorno. Los impactos se ciernen sobre la mayoría de la especie humana que no tiene manera de enfrentarlos y salir adelante.

Tenemos la sospecha de que la especie humana no ha estado a la altura de ser la conciencia de sí de la vida del mundo. Lo que aparece a todas luces es que está en peligro la vida en el planeta y dentro de ella, la humana. El punto no es salvar el planeta, sino la vida en el planeta Tierra. La Tierra podría continuar como tantos planetas que existen sin vida; por eso, los riesgos que afrontamos y los desastres que enfrentaremos exigen que tomemos las medidas pertinentes. Esto es hacer lo que corresponde y es lo que una verdadera conciencia inteligente debería hacer. Debemos de establecer una relación ética con la naturaleza de la misma forma que la tenemos entre los seres humanos, con los animales, las plantas y la vida en general. ¿Cuál es el comportamiento adecuado con la naturaleza?, ¿qué significa hacer lo que corresponde en relación con ella?

\section{Una nueva propuesta: saber vivir en el mundo}

¿Cómo se debería llamar a hacer lo que corresponde en relación con el ambiente o con la naturaleza? Tomando nota de lo señalado en los puntos anteriores, las dificultades en el significado de lo que entendemos por vida y la lamentable práctica humana en relación con el planeta, es conveniente que planteemos algunas ideas para encarar el desafío de hacer lo que corresponde en este caso.

¿Cómo se llama a esta relación? ¿Cómo llamaríamos a esta relación del ser humano con la naturaleza? Pensamos que podríamos entenderla como la sabiduría de la vida buena, del saber vivir en el mundo.

\subsection{Una nueva mirada comprehensiva, la interdisciplinariedad}

Si la especie humana pretende ser la conciencia de sí del mundo, debe asumir entonces los retos de lo que hemos llamado hacer lo que corresponde en relación con lo que consideramos lo central: la vida buena, vinculada con los seres vivos y el planeta.

Esta orientación exige una ética comprensiva, que se funda en una mirada interdisciplinaria de las cosas y de la realidad. Los enfoques 
altamente especializados y solo disciplinares no tienen elementos para poder proponer juicios éticos adecuados sobre la realidad y los problemas que están relacionados con la naturaleza y el ambiente. Son enfoques rígidos y que no tienen la capacidad de una mirada integral de las cosas.

Toda mirada interdisciplinaria parte de asumir que la realidad es compleja y diversa. Reconoce, además, que una mirada o solo un enfoque no nos permite comprender las cosas y, por ende, debilita nuestra capacidad de acción.

La mirada interdisciplinaria busca ser comprehensiva, y en eso, se da la mano con el esfuerzo inherente de la ética. Si queremos hacer lo que corresponde debemos partir necesariamente de esta visión comprehensiva de la realidad. Tanto el juicio ético como el comportamiento adecuado necesitan de una perspectiva muy amplia en el conocimiento de la realidad. Los temas de deforestación, del agua, de los gases de efecto invernadero, de las energías renovables, de los conflictos de la minería, de las políticas ambientales, del respeto a los animales y a los seres vivos, obligan a contar con una visión holística del mundo y de la actividad humana. Sin ella, nuestra práctica se vuelve un comportamiento sin sentido y sin ninguna posibilidad de éxito.

El mundo es uno y diverso. De la misma manera que naturaleza humana es una y diversa. Emitir un juicio ético sobre si algo es bueno o no lo es, exige mucho entrenamiento, capacidad de discernimiento y prudencia. Esto exige comprender la complejidad del mundo.

\subsection{La sostenibilidad, un horizonte para la acción y el desarrollo}

La interdisciplinariedad es una cuestión de amplitud de miras y de renovado esfuerzo por comprender las cosas y orientar la práctica humana. En esa orientación, lo que se ha venido en llamar la sostenibilidad afirma y remarca la idea de la acción práctica, adecuada, integral y a largo plazo. Lo sostenible significa una respuesta integral a desafíos complejos que desbordan las prácticas unilaterales y sin aliento.

Decimos que la sostenibilidad representa un horizonte de la práctica social y ambiental del mundo de hoy porque percibe la precariedad de las salidas inmediatas y sin sentido. La sostenibilidad es un nuevo sentido en el obrar (ONU 2015).

Tomar nota de los fundamentos de la sostenibilidad va más allá de pensar y afirmar que los proyectos deben trascender y deben tener los resultados esperados. La sostenibilidad no debe ser confundida con la exigencia de la rentabilidad ni del cumplimiento de indicadores. Nada más lejano al horizonte de la sostenibilidad.

La sostenibilidad exige una mirada interdisciplinaria y el esfuerzo comprensivo de la ética para poder vivir en el mundo, en primer lugar, sin dañarlo; en segundo lugar, respetando y conviviendo con todas las formas de 
vida existentes; y finalmente, permitiendo la realización de la vida humana. Ese es el horizonte de la sostenibilidad.

Un mundo sostenible es el mundo donde el ser humano asume su papel ético de responsabilidad para con el planeta, para con la vida y para consigo mismo.

\subsection{Saber vivir en el mundo, el paradigma de la vida buena}

Quizá la vieja enseñanza de todos los pueblos antiguos de saber vivir en el mundo puede ser hoy muy útil (Farah y Vasapollo 2011) ${ }^{10}$. La depredación, la contaminación y la explotación indiscriminada de recursos, de seres vivos, y de seres humanos no expresan de ninguna manera una verdadera vida buena. La comprensión del mundo a través de una mirada interdisciplinaria y el horizonte de la sostenibilidad son aspectos fundamentales de la construcción de la ciencia, por un lado, y de la acción y la práctica por el otro.

Una vida humana que conoce a la naturaleza, que la respeta, y que vive en concordancia con ella — es decir, que su corazón palpita al unísono con ella-y que, por ello la comprende, puede ser el nuevo paradigma de una vida buena, primero en relación con el ambiente, segundo, con los otros seres vivos, y tercero, en la relación de los ciudadanos entre sí. Con ello debemos superar el penoso antropocentrismo del que lamentablemente siempre hemos hecho gala los seres humanos.

\section{Referencias}

ARISTóTElEs (1985). «Nicomachean Ethics». En Barnes 1985: 1729 - 1867.

ARISTÓTELES (1985b). «Politics». En Barnes 1985: 1986 - 2129.

ARISTóteles (1993). Parva Naturalia. Jorge Serrano (traductor). Madrid: Alianza Editorial.

BARNES, JonATHAN (editor) (1985).The complete works of Aristoteles. New Jersey: Princenton Universty Press.

Blanché, RoBert (1980). El método experimental y la filosofía de la física. México: Fondo de Cultura Económica.

Descartes, René (1967). «Carta a los Señores Decanos y Doctores de la Sagrada Facultad de Teología de París, Meditaciones Metafísicas». En: Descartes, René. Obras Escogidas. Buenos Aires: Editorial Sudamericana, pp. 202.

10 Una de estas expresiones es, por ejemplo, la interesante discusión llevada a cabo en La Paz, Bolivia sobre el sentido del Buen Vivir. 
EINSTEIN, ALBERT (1980 [1933]). «On the method of theoretical physics». En: Blanché 1980: 422.

Giddens, Anthony (2010). La Política del Cambio Climático. Madrid: Alianza Editorial.

Gilson, Étienne (1976). La filosofía en la Edad Media. Desde los orígenes patrísticos hasta el fin del siglo XIV. Madrid: Editorial Gredos.

KIRK, G.S. y J.E. RAVEN (1981). Los filósofos presocráticos. Madrid: Editorial Gredos.

LEIBNIZ, GotTFRIED (1980 [1957]). «Correspondance avec Clarke». En: Blanché 1980: 184-185.

MacIntyre, Alasdair (1982). Historia de la ética. Barcelona: Ediciones Paidós.

MaCINTYRE, ALASDAIR (1987). Tras la Virtud. Barcelona: Editorial Crítica.

Mondolfo, Rodolfo (1968). Figuras e Ideas de la Filosofía del Renacimiento. Buenos Aires: Editorial Losada, S.A.

ORganización de Naciones Unidas (2015). Transformar nuestro mundo: la Agenda 2030 para el Desarrollo Sostenible. Documento en Pdf.

Platón (1986). República. Madrid: Editorial Gredos. 